\title{
JMR Announces Major Reduction in Publication Time Among Other Changes
}

Several major improvements to the Journal of Materials Research (JMR) and its operations should enhance the quality and timeliness of the journal. The highlights of the improvements include a reduction of more than seven months in the average publication time and an increase in the quality of published papers.

Statistics for the last four months of 1999 show that the average time required to publish an article, that is, the time from submission to publication, has been reduced to 9.5 months from 17 months a year ago, with $80 \%$ of the articles published in 12 months or less. This improvement resulted from several factors: (1) a sixmonth backlog of manuscripts, which had been accepted and were awaiting publication, was eliminated by printing several expanded issues; (2) the time required for reviewing and revising manuscripts has been reduced on the average by more than one month by tightening time limits for each step of the process; and (3) the production time after a manuscript has been accepted, which includes copy editing, typesetting, printing, and mailing, was reduced by more than two months by combining all these operations under one roof.
To enhance the quality of published papers, standards and requirements for acceptance of articles have been raised, and review procedures have been tightened.

Some IMR publication delays resulted from an inadequate software system for tracking manuscripts. To allow efficient tracking of manuscripts through all phases of the editorial and publication processes, the editorial office recently installed new software. The enhanced capabilities of the new software will identify manuscripts that are overdue in each stage of the review and publication processes and send memoranda to the individuals responsible. It will also enable generation of statistics on how well the journal is doing and identify where improvements need to be made. With these capabilities, JMR expects to reduce the review time still further.

$J M R$ subscribers may now access the full text of the journal electronically on the MRS website several weeks before the print edition is available. All papers, including figures and micrographs, appear online. This benefit is available only to individuals and institutions that subscribe to JMR.
MRS members will continue to be able to view JMR rapid communications and $J M R$ Abstracts online. JMR Abstracts service provides titles, abstracts, author names and their affiliations for all articles and rapid communications approximately one month prior to the publication date of the journal. Beginning with this issue of the MRS Bulletin, instead of the full text of each $J M R$ abstract, only the title and author listing for each article appears in print. In addition to each title and author listing, a direct link through the MRS website is provided to view the abstract online. See $J M R$ Abstracts on page 71 to view the change.

As JMR begins its 15th year of publication, the hard work and dedication of all the editors and the editorial staff at MRS Headquarters have positioned JMR to serve the international materials research community as its leading archival journal. Members of the materials community are urged to submit their research findings to $J M R$ for publication.

ROBERT P. FRANKENTHAL Editor-in-Chief Journal of Materials Research

\section{Undergraduate Materials Research Initiative Funds $\mathbf{4 0}$ Projects}

In the second year of the Materials Research Society's Undergraduate Materials Research Initiative (UMRI), coordinated by the MRS Academic Affairs Committee, 40 undergraduate student projects have been chosen to receive a $\$ 1,000$ grant each to support the students' materials-related projects. MRS also presented Honorable Mentions. Beth Stadler of the University of Minnesota and chair of the Academic Affairs Committee said that the number of awards has doubled from last year's. The award recipients for 1999 and 2000 will be acknowledged at the 2000 MRS Spring Meeting in San Francisco when their posters are displayed at the Education Workshop symposium.

The UMRI program was designed to introduce undergraduate students to the excitement of discovery through research in materials science and engineering. Under the program, a grant of no more than $\$ 750$ is provided for the cost of a moderate research project. An additional award of $\$ 250$ is payable directly to the undergraduate researchers upon completion of the project. Researchers from small institutions are particularly encouraged in order to attract promising students to materials research who might not have other funding available.

The awards for 2000 were announced in November 1999, and the list of recipients was posted at the 1999 MRS Fall Meeting in Boston.

\section{Oludurotimi Adetunji} Characterization of High Temperature Solution Growth of $\mathrm{Cr} 2+\mathrm{CdS}$. Fisk University Jean-Oliver Ndap, Advisor

Daniel Allen

Blend-Based Photovoltaic Devices

Cornell University

George Malliaras, Advisor

Melinda Allen

Materials Analysis with Rutherford

Backscattering Spectrometry

Colorado School of Mines

Uwe Greife and Peter Sutter, Advisors

\section{Undergraduate Materials Research Initiative Grant Recipients}

\section{Ilke Arslan}

Developing an Atomic Scale Understanding of the Structure Property Relationships of Dislocation Cores in GaN University of Illinois, Chicago Nigel D. Browning, Advisor

Scott Barry

Investigation of a New Four-Layer Ruthenium-Based Cuprate, $\mathrm{Ru}_{2} \mathrm{LnSr}_{2} \mathrm{Ln}^{\prime} \mathrm{Cu}_{2} \mathrm{O}_{11}(\mathrm{Ru}-2312)$ ( $\mathrm{Ln}$ $=$ Lanthanide)

Beloit College

George Lisensky, Advisor

Elvin Beach

Investigation of the Effects of Relative
Humidity Level on Adhesion Forces between Pharmaceutical Powders and Storage Surface Materials using Atomic Force Microscopy Michigan Technological University Jaroslaw Drelich, Advisor

Douglas Burnett

Pulse Plating of Ultrathin-Layered Magnetic Films

Washington State University KNona C. Liddell, Advisor

Blaine Butler

Influence of Substrate Surface Chemistry on the Binding of DNARecA Protein Complexes
James Madison University Brian H. Augustine, Advisor

Kerianne Cullen

DNA Detection using Colloidal Gold Nanoparticles: Toward near Patient DNA Diagnostics

Virginia Commonwealth University Anthony Guiseppi-Elie, Advisor

Niall Donnelly

Measurement of Electromechanical

Strain in PMN-PT Thin Film Structures

Queens University, Belfast

J.M. Gregg, Advisor 